\title{
Lixiviação do sulfentrazone em solos do Norte de Minas Gerais cultivado com cana-de-açúcar
}

\author{
Leaching sulfentrazone in North soils of Minas Gerais cultivated with \\ sugar cane
}

\begin{abstract}
Matheus Ferreira França Teixeira ${ }^{1 *}$, Lucas Christian Lima de Andrade ${ }^{1}$, Evandro Marcos Biesdorf ${ }^{1}$, Elivelton Maciel Biesdorf ${ }^{2}$, Wendel Magno Souza ${ }^{1}$, Gefferson Pereira da Paixão ${ }^{1}$, Naira Moreli de Freitas ${ }^{3}$
\end{abstract}

Resumo - Diante da intensa utilização de herbicidas, aliada à escassez de informações referentes ao efeito residual desses compostos em alguns solos brasileiros, objetivou-se neste trabalho avaliar o potencial de lixiviação por meio de ensaios biológicos, do herbicida sulfentrazone, nas camadas de 0-20 e 20-40 cm de solos do Norte de Minas Gerais cultivado com cana-de-açúcar. O experimento foi conduzido no esquema de parcelas subdivididas, no delineamento inteiramente casualizado. As parcelas foram compostas por colunas de PVC, preenchidas com solos de Salinas (MG) e Pirapora (MG), e as subparcelas, por 10 profundidades com intervalos de $5 \mathrm{~cm}(0-5,5-10,10-15,15-20,20-25$, $25-30,30-35,35-40,40-45$ e $45-50 \mathrm{~cm}$ ). No topo das colunas, aplicou-se a dose de $600 \mathrm{~g}^{-1}$ i.a sulfentrazone e, 12 horas depois, simulou-se $60 \mathrm{~mm}$ de precipitação pluviométrica. Após 72 horas, as colunas foram colocadas na posição horizontal e abertas longitudinalmente, divididas em subseções de 5,0 cm. A avaliação da intoxicação das plantas-teste foi realizada visualmente aos 21 dias após a semeadura destas, posteriormente foi feito o corte da parte aérea das plantas bioindicadoras. Foram observados sintomas de intoxicação do sulfentrazone nas plantas bioindicadoras até $10 \mathrm{~cm}$ de profundidade na camada superficial $(0-20 \mathrm{~cm})$ e até $15 \mathrm{~cm}$ na camada mais profunda $(20-40 \mathrm{~cm})$ de ambos os solos. Nas duas camadas de solo o sulfentrazone foi detectado em maior concentração nos primeiros cinco centímetros. Maior mobilidade do herbicida foi verificada na camada mais profunda do solo $(20-40 \mathrm{~cm})$ indicando maior potencial de lixiviação do herbicida nestas condições. Palavras-chave: sorção, profundidades, mobilidade

Abstract - In view of the intense use of herbicides, coupled with the scarcity of information regarding the residual effect of these compounds in some Brazilian soils, the objective of this study was to evaluate the leaching potential by means of biological assays of the sulfentrazone herbicide in the $0-20$ and 20-40 cm of soils of the North of Minas Gerais cultivated with sugarcane. The experiment was conducted in the split - plot scheme, in a completely randomized design. The plots were composed of PVC columns, filled with soils of Salinas (MG) and Pirapora (MG), and the subplots, for 10 depths with intervals of $5 \mathrm{~cm}(0-5,5-10,10-15,15-20,20-25,25-30,30-35,35-40,40-45$ and $45-50 \mathrm{~cm})$.

Recebido: Junho 03, 2017. Aceito: Setembro 05, 2017.

${ }^{1}$ Universidade Federal de Viçosa - UFV, Campus Universitário, Av. P. H. Rolfs, s/n, CEP 36570-000, Viçosa, MG, Brasil. E-mail: teixeiramff@gmail.com; lucaschristian91@gmail.com; evandromarcospva@hotmail.com; wendel. souza@ufv.br; geffersonpaixao@yahoo.com.br

${ }^{2}$ Instituto Federal de Educação - IFMT, Campus São Vicente, São Vicente, MT, Brasil.

E-mail: elivelton.biesdorf@agronomo.eng.br

${ }^{3}$ Programa de Pós-graduação em Agronomia - PGA, Universidade Estadual de Maringá - UEM, Maringá, PR, Brasil. E-mail: nairamoreli@gmail.com 
At the top of the columns the dose of $600 \mathrm{~g}$ a.i. ha- $\mathrm{ha}^{-1}$ of sulfentrazone was applied and 12 hours later, $60 \mathrm{~mm}$ of rainfall was simulated. After 72 hours, the columns were placed horizontally and opened longitudinally, divided into subsections of $5.0 \mathrm{~cm}$. The evaluation of intoxication of the test plants was performed visually at 21 days after sowing, after which the aerial part of the bioindicator plants was cut. Symptoms of sulfentrazone intoxication were observed in the bioindicator plants up to $10 \mathrm{~cm}$ deep in the superficial layer $(0-20 \mathrm{~cm})$ and up to $15 \mathrm{~cm}$ in the deepest layer $(20-40 \mathrm{~cm})$ of both soils. In the two soil layers the sulfentrazone was detected in a higher concentration in the first five centimeters. Greater mobility of the herbicide was verified in the deeper layer of the soil (20-40 cm) indicating a greater leaching potential of the herbicide under these conditions.

Keywords: sorption, depths, mobility

\section{Introdução}

No cenário agrícola mundial, o Brasil figura como um dos maiores produtores de cana-de-açúcar, o que se deve à grande área cultivada e à elevação da produtividade nos últimos anos (CONAB, 2015). Este fato correlaciona-se diretamente aos avanços tecnológicos e as modernizações no sistema de cultivo, permitindo assim o plantio em áreas extensas. A tecnologia empregada veio como uma saída para a substituição da mão-de-obra que está cada vez mais escassa no campo, além de promover maior praticidade nas operações. Dentre esses avanços tecnológicos, destaca-se o uso de herbicidas no controle de plantas daninhas, visando minimizar a interferência causada pelas mesmas para as culturas (Freitas et al., 2012).

Devido aos sistemas intensivos de cultivo na agricultura, a larga utilização além do manejo incorreto desses produtos, os herbicidas frequentemente são detectados em estudos de qualidade das águas superficiais e subterrâneas (Carter, 2000; Tanabe et al., 2001), sendo que a cultura da cana-de-açúcar é uma das que mais utiliza-se herbicidas para o controle de plantas infestantes por unidade de área cultivada (Southwick et al., 2002). Além disso, essa cultura possui um ciclo relativamente longo, sendo necessária a aplicação de herbicidas de elevada persistência no solo para que o controle seja eficiente.

O estudo do comportamento desses produtos no solo vem ganhando destaque nos últimos anos, sendo que são diversos os processos que influenciam na dinâmica dos herbicidas no solo (Melo et al.,2010). Dentre esses processos tem-se o fenômeno da lixiviação que é a principal forma de mobilidade de moléculas solúveis em água no solo. Esse transporte ocorre no perfil do solo, pela diferença de potencial osmótico entre dois pontos, acompanhando o fluxo de água (Prata et al., 2003). A lixiviação é de suma importante para que o herbicida movimente no solo, fazendo com que sementes de plantas daninhas ou plantas em germinação sejam atingidas, promovendo o controle. Por outro lado, se o processo for acentuado o herbicida poderá ser carreado a camadas mais profundas do solo, podendo contaminar águas subterrâneas, além de limitar sua ação, tornando o controle ineficiente (Curran, 2016). Um aspecto importante a ser ressaltado é que a lixiviação de herbicidas para camadas mais profundas pode aumentar o tempo de permanência dos produtos no ambiente, dada a menor atividade microbiológica (Sarmah et al., 1998; Prata et al., 2001).

Na região semiárida, devido ao plantio de culturas como a cana-de-açúcar, dentre os herbicidas amplamente utilizados destaca-se o sulfentrazone, (N - [2,4-dicloro-5-[4-(difluorometil)4,5-diidro-3 metil -5-oxo-1H- 1,2,4-triazol-1-il] metanosulfonamida) (Tabela 1), que pertence ao grupo químico das aril-triazolinonas, sua ação pode ser sistêmica ou por contato, podendo ser absorvido pelas raízes e folhas, com translocação primária no apoplasto e movimento limitado no floema. Age na inibição da PROTOX, envolvida 
na biossíntese de clorofila, e por consequência há o acúmulo de protoporfina IX, causando peroxidação do oxigênio e a destruição das membranas celulares (Reddy e Locke, 1998).

O sulfentrazone é classificado como pouco volátil (pressão de vapor de 1 x $10^{-9} \mathrm{mmHg}$ a $25^{\circ} \mathrm{C}$ ). A degradação microbiana é considerada a principal forma de dissipação do herbicida. A solubilidade em água muda com o $\mathrm{pH}$, sendo de 110,780 , e $1.600 \mathrm{mg} \mathrm{L}^{-1}$ a pH 6,0; 7,0 e 7,5, respectivamente. Este herbicida é caracterizado como hidrofílico, apresentando coeficiente de partição octanol-água $\left(\mathrm{K}_{\text {ow }}\right)$ de 9,8 (Rodrigues e Almeida, 1998). O sulfentrazone é um ácido fraco com constante de dissociação (pKa) de 6,56 (Tomlin, 2011). Desta forma, esse herbicida pode apresentar alta persistência em sistemas aquáticos, podendo causar sérios problemas ambientais. O sulfentrazone é um herbicida utilizado em pré-emergência para o controle de plantas daninhas dicotiledôneas em diversas espécies monocotiledôneas, como a cana-de-açúcar (Carbonari et al., 2016)

Tabela 1. Fórmula estrutural e características do sulfentrazone.

\begin{tabular}{cl}
$\begin{array}{c}\text { Fórmula } \\
\text { estrutural }\end{array}$ & \multicolumn{1}{c}{ Características } \\
& $\begin{array}{l}\text { Fórmula molecular: } \\
\text { C11H10Cl2F2N4O3S } \\
\end{array}$ \\
\end{tabular}

Fonte: ChemSpider (2017).
Praticamente não existem estudos sobre o comportamento de herbicidas em solos da região norte do estado de Minas Gerais. Devido às características próprias desses locais tais como fatores climáticos e ecológicos que influenciam diretamente nos processos de mineralização e intemperismo, os solos dessas regiões semiáridas apresentam características físicas, químicas e mineralógicas diferentes daquelas observadas nas regiões de clima tropical de altitude com verão chuvoso e temperaturas amenas, pois em geral, os primeiros são menos intemperizados, possuem $\mathrm{pH}$ alcalino, com baixa concentração de carbono orgânico e frequentemente possuem alta concentração de sais (Braga, 2014).

Diante da intensa utilização de herbicidas, aliada à escassez de informações referentes ao efeito residual desses compostos em alguns solos brasileiros, objetivou-se neste trabalho avaliar o potencial de lixiviação do herbicida sulfentrazone em diferentes camadas de solos da região Norte do estado Minas Gerais por meio de bioensaios.

\section{Material e métodos}

Para condução do experimento foram coletadas amostras de solo nas camadas de 0-20 cm e 20-40 cm, classificados como Latossolo Vermelho-Amarelo no município de Salinas - MG e Espodossolo no município de Pirapora - MG, cujos atributos estão apresentados na (Tabela 2).

A região norte de Minas Gerais apresenta clima tropical (Aw), em que chove menos no inverno que no verão. A temperatura média é de $23.0^{\circ} \mathrm{C}$

Tabela 2. Atributos químicos e físicos dos solos coletados no município de Salinas MG e Pirapora MG, nas profundidades de $0-20 \mathrm{~cm}$ e 20 a $40-\mathrm{cm}$.

\begin{tabular}{|c|c|c|c|c|c|c|c|}
\hline & $\begin{array}{c}\text { Profundidade } \\
\mathrm{cm}\end{array}$ & $\begin{array}{l}\mathrm{pH} \\
\mathrm{H}_{2} \mathrm{O}\end{array}$ & $\begin{array}{c}\text { Mat. Orgânica (MO) } \\
\text { dag kg-1 }\end{array}$ & $\begin{array}{c}\text { CTC (T) } \\
\text { cmol }_{c} \mathbf{d m}^{-3}\end{array}$ & $\begin{array}{c}\text { Areia } \\
\%\end{array}$ & $\begin{array}{c}\text { Silte } \\
\%\end{array}$ & $\begin{array}{c}\text { Argila } \\
\%\end{array}$ \\
\hline \multirow{2}{*}{ Salinas - MG } & $0-20$ & 5,5 & 2,18 & 3,92 & 52 & 22 & 26 \\
\hline & $20-40$ & 5,2 & 1,45 & 3,62 & 51 & 19 & 30 \\
\hline \multirow{2}{*}{ Pirapora - MG } & $0-20$ & 5,3 & 2,01 & 4,05 & 55 & 18 & 27 \\
\hline & $20-40$ & 5,0 & 1,37 & 3,77 & 50 & 15 & 35 \\
\hline
\end{tabular}

(pH): Potencial hidrogeniõnico; (MO): Matéria Orgânica; (T): Capacidade de Troca Catiônica. Análises realizadas no Laboratório de Análises de Solo Viçosa, segundo a metodologia da EMBRAPA (1997). 
e a pluviosidade média anual é cerca de $880 \mathrm{~mm}$ (Köppen e Geiger, 1928).

O experimento foi conduzido no esquema de parcelas subdivididas, distribuídas no delineamento inteiramente casualizado (DIC), com quatro repetições. As parcelas foram compostas pelas colunas preenchidas com as amostras dos dois solos coletados nas duas camadas $(0-20 \mathrm{~cm}$ e $20-40 \mathrm{~cm}$ de profundidade), em áreas sem histórico de aplicação de herbicidas. As colunas foram segmentadas em 10 profundidades, com intervalos de $5 \mathrm{~cm}(0-5,5-10,10-15,15-20$, $20-25,25-30,30-35,35-40,40-45$ e $45-50 \mathrm{~cm}$ ) que corresponderam às sub-parcelas.

As amostras dos solos foram secas ao ar, destorroadas e passadas em peneiras com malha de $4 \mathrm{~mm}$. De cada amostra de solo, foi retirada uma sub-amostra para realização de análises químicas e físicas segundo metodologia descrita pela EMBRAPA (1997) e análise mineralógica, onde a separação da fração argila dos solos estudados foi realizada de acordo com EMBRAPA (1997), além de identificação dos minerais conforme Chen (1977).

Para avaliação da lixiviação foram utilizadas colunas de PVC com $50 \mathrm{~cm}$ de comprimento e $10 \mathrm{~cm}$ de diâmetro, seccionadas a cada $5 \mathrm{~cm}$ e com tampa lateral removível (Figura 1), segundo metodologia utilizada por Freitas et al. (2012), e as colunas foram parafinadas internamente para evitar escoamento lateral. Após o preenchimento com as amostras de solo, estas foram saturadas com água, por um período de 48 horas e deixadas, posteriormente, na posição vertical, em repouso, por 72 horas, visando à drenagem do excesso de água.

Posteriormente, aplicou-se o herbicida sulfentrazone, no topo das colunas, na dose de $600 \mathrm{~g}$ i.a. ha ${ }^{-1}$. Doze horas após a aplicação do herbicida, procedeu-se à simulação da precipitação pluviométrica, com a aplicação de lâmina única de $60 \mathrm{~mm}$, por um período de três horas. Após a simulação da precipitação pluviométrica, as colunas foram mantidas por 72 horas na posição vertical, de modo a permitir a percolação da água no solo e, posteriormente, estas foram colocadas na posição horizontal, quando foi feita a abertura lateral e seccionamento a cada $5 \mathrm{~cm}$ com lâmina de PVC.

Após a abertura da coluna coletou-se amostras de solo em cada uma das sub-profundidades. Estas amostras foram colocadas em recipientes com capacidade de $300 \mathrm{~cm}^{3}$ onde foi semeado 4 sementes de sorgo (Sorghum bicolor), por segmento da coluna, como espécie bioindicadora da presença do sulfentrazone, sendo esta espécie altamente sensível a presença deste herbicida.

Aos 21 dias após a semeadura da espécie indicadora, realizou-se a avaliação da mobilidade do herbicida, analisando o índice de intoxicação e o acúmulo de matéria seca das plantas. Na avaliação do índice de intoxicação das plantas indicadoras, foram atribuídas notas de 0 (ausência de intoxicação) a 100 (morte da planta). Para avaliação da matéria seca, todas as plantas foram cortadas à superfície, rentes ao solo, e posteriormente colocadas em estufa com circulação forçada de $\operatorname{ar}\left(70 \pm 2{ }^{\circ} \mathrm{C}\right)$ até atingir massa constante.

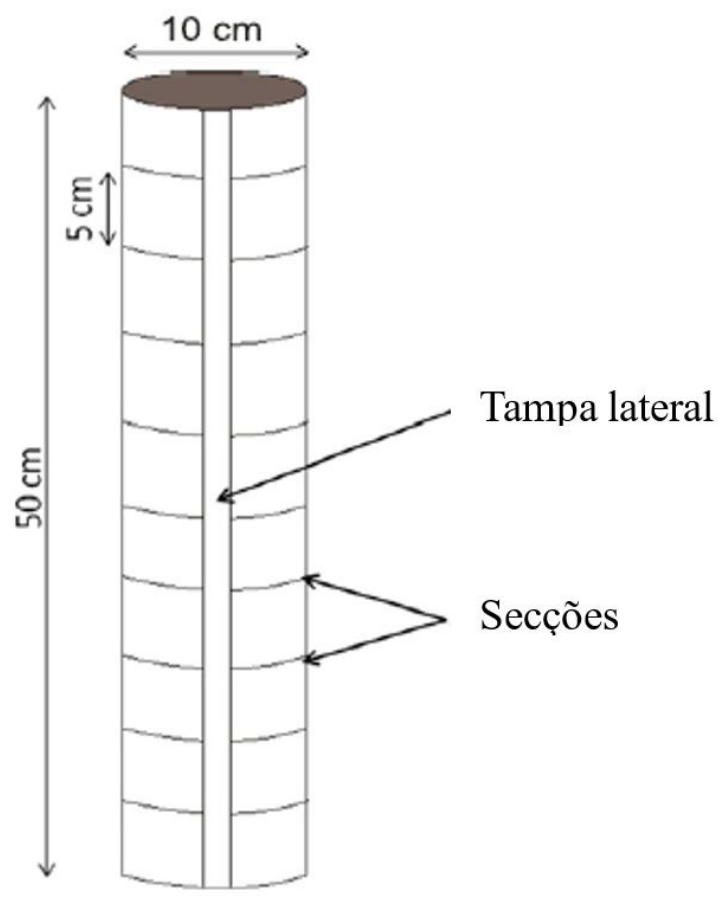

Figura 1. Esquema de coluna utilizada na montagem do experimento. 
Para os gráficos de intoxicação e massa da matéria seca da planta indicadora do sulfentrazone em função da profundidade, utilizou-se o modelo de barras com desvio padrão, no eixo $\mathrm{Y}$ a profundidade e no eixo $\mathrm{X}$ a intoxicação e massa seca respectivamente. Foi utilizado o programa SigmaPlot 12.5 (Exact graphs e data analysis) para Windows.

\section{Resultados e discussão}

Observou-se intoxicação nas plantas de sorgo, evidenciando a presença do sulfentrazone nos solos coletados na camada de $0-20 \mathrm{~cm}$, até a profundidade de $10 \mathrm{~cm}$ na coluna, com maior intensidade na primeira secção da coluna $(5 \mathrm{~cm})$
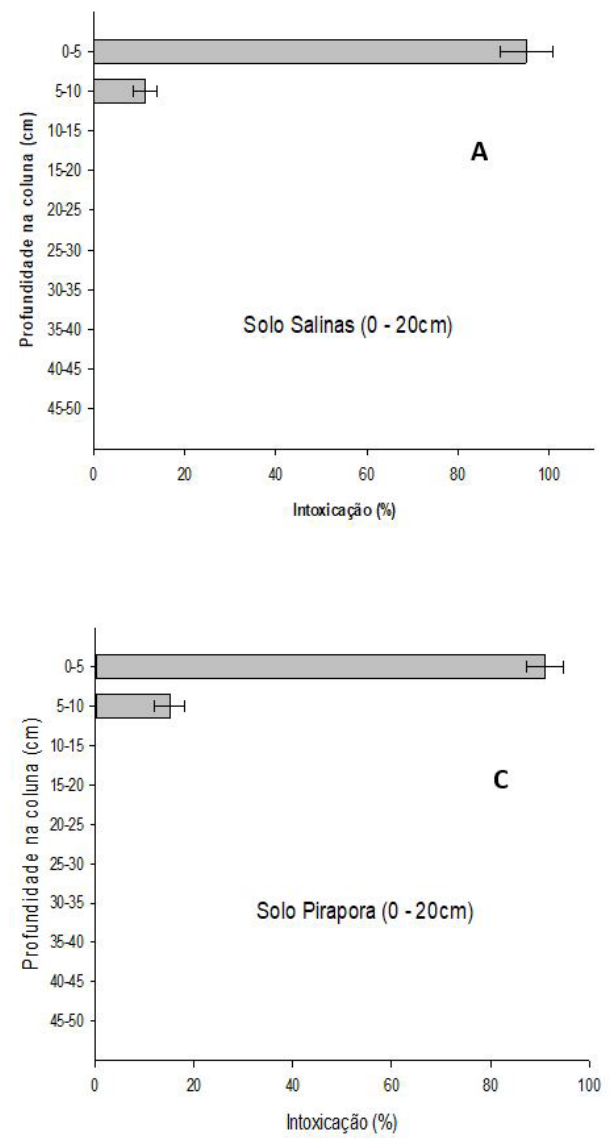

(Figura 2A). Para os solos coletados na camada de $20-40 \mathrm{~cm}$, verificou-se intoxicação das plantas bioindicadoras até a profundidade de $15 \mathrm{~cm}$, também, com maior intensidade na profundidade de $0-5 \mathrm{~cm}$ (Figura 2B), indicando que maior proporção do herbicida ficou retida nos primeiros cinco centímetros de profundidade das colunas para os dois solos estudados, conforme ilustrado nas Figuras 2A-D, nas quais se verifica drástica redução no acúmulo de matéria das plantas bioindicadoras.

A maioria das sementes de plantas infestantes estão localizadas na camada de $5 \mathrm{~cm}$ de solo. Sendo assim, a maior mobilidade do herbicida no perfil do solo, reduz sua concentração nessa
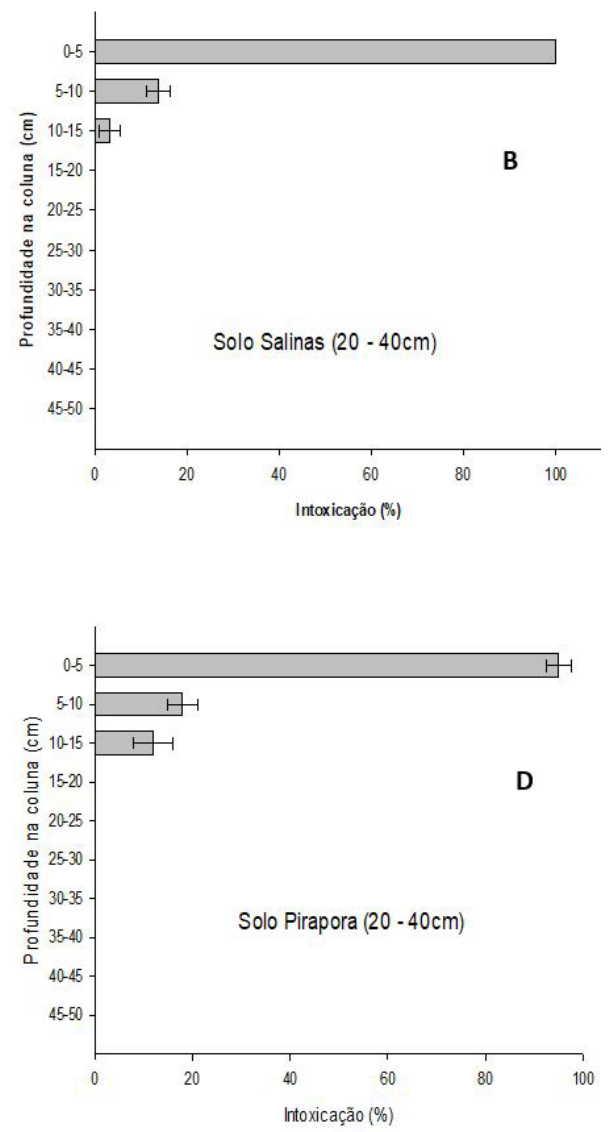

Figura 2. Porcentagem de intoxicação das plantas de sorgo em diferentes profundidades das colunas, no solo de Salinas-MG coletados nas profundidades de (A) 0 a $20 \mathrm{~cm}$ e (B) 20 a $40 \mathrm{~cm}$ e no solo de Pirapora-MG coletados nas profundidades de (C) 0 a $20 \mathrm{~cm}$ e (D) 20 a $40 \mathrm{~cm}$, após aplicação de sulfentrazone e simulação de chuva de $60 \mathrm{~mm}$. 
camada inicial, comprometendo a eficácia do produto no controle das plantas daninhas (Braga, 2014). No entanto, para um bom controle de plantas daninhas com herbicidas aplicados em pré-emergência, especialmente para aquelas com sementes de maior tamanho como corda-de-viola (Ipomoea sp) e leiteiro (Euphorbia heterophylla), é interessante que o herbicida apresente razoável mobilidade, entre 10 e $15 \mathrm{~cm}$, conforme verificado nos solos estudados neste trabalho, de modo à otimizar o controle, pois as sementes destas plantas se encontram em profundidades maiores.

Braga (2014) avaliando potencial de lixiviação do sulfentrazone em cinco solos da região canavieira do Nordeste brasileiro detectou o herbicida por meio de bioensaio e cromatografia em profundidades que variaram de 15 a $45 \mathrm{~cm}$, dependendo do solo, sendo que no Neossolo Quartzarênico testado pelos autores (RQ), com baixo teor de argila (2\%) e matéria orgânica $(0,57 \%)$, o sulfentrazone foi detectado até a profundidade de $45 \mathrm{~cm}$, indicando elevado potencial de lixiviação do herbicida neste solo, o que resultou na redução da concentração do herbicida nos primeiros $10 \mathrm{~cm}$ das colunas, comprometendo sua eficácia no controle de plantas infestantes.

Segundo Braga (2014), a mobilidade do herbicida no perfil do solo pode ser benéfica para herbicidas que exercem seu efeito sobre sementes ou plântulas durante a germinação ou emergência, mas em excesso pode acarretar redução da eficácia pela percolação do composto no perfil do solo, além da possibilidade de contaminação de águas subterrâneas.

Geralmente em solos mais argilosos os herbicidas tendem a ficar mais sorvidos aos coloides do solo, diminuindo sua mobilidade no perfil do solo. No trabalho mencionado anteriormente, observou-se resultado semelhante ao verificado nesta pesquisa, maior mobilidade do sulfentrazone foi constatada mesmo em solos com maior teor de argila e matéria orgânica, o que se deve, provavelmente, ao tipo de argila. Segundo Silva e Silva (2007), em diversos casos, não há correlações entre a sorção do herbicida e os teores de argila. Isso ocorre porque as características químicas das argilas dependem do material de origem do solo e do grau de intemperismo deste, o que varia muito em condições tropicais (Alfonso et al., 2017).

O sulfentrazone apresentou elevado potencial de translocação vertical, ou seja, alta mobilidade, nos dois solos avaliados, nas duas camadas, sendo esta menor no Espodossolo. Neste solo, o herbicida permaneceu nas camadas superiores da coluna enquanto que nos demais ocorreu distribuição do herbicida ao longo destas. Porém o solo que reteve a maior concentração do composto nas primeiras profundidades da coluna foi o que possuía o maior teor de argila.

O menor teor de matéria orgânica e CTC efetiva do solo da camada mais profunda $(20-40 \mathrm{~cm})$ pode ser a razão da maior mobilidade do herbicida. Sabe-se que o valor de $\mathrm{K}_{\mathrm{ow}}$ de um herbicida está diretamente relacionado a sua sorção aos coloides orgânicos do solo. Sendo que maiores valores de $\mathrm{K}_{\mathrm{ow}}$ tendem a proporcionar maior retenção da molécula do herbicida nos coloides orgânicos do solo. Sendo assim quanto maior o teor de matéria orgânica do solo, maior a tendência do herbicida estar sorvido ao mesmo. Procópio et al. (2001) verificaram aumento na ocorrência de efeitos fitotóxicos do s-metolachlor às culturas e maior probabilidade de contaminação de águas subterrâneas em solos com baixo valor de CTC efetiva.

Confirmando os resultados obtidos com a avaliação de intoxicação, verificou-se que nos primeiros cinco centímetros houve drástica redução no acúmulo de matéria seca em relação aos demais seguimentos da coluna (Figuras 3A e 3B). Todavia, apesar da intoxicação moderada verificada até 10 e $15 \mathrm{~cm}$ para os solos coletados nas profundidades de 0-20 e 20-40 cm, respectivamente, não se verificou alteração no acúmulo de matéria seca, indicando que a avaliação visual da intoxicação é de certa forma mais eficiente para se avaliar o potencial de lixiviação de herbicidas em relação ao acúmulo de matéria seca, conforme relatado por Freitas et al. (2012). 

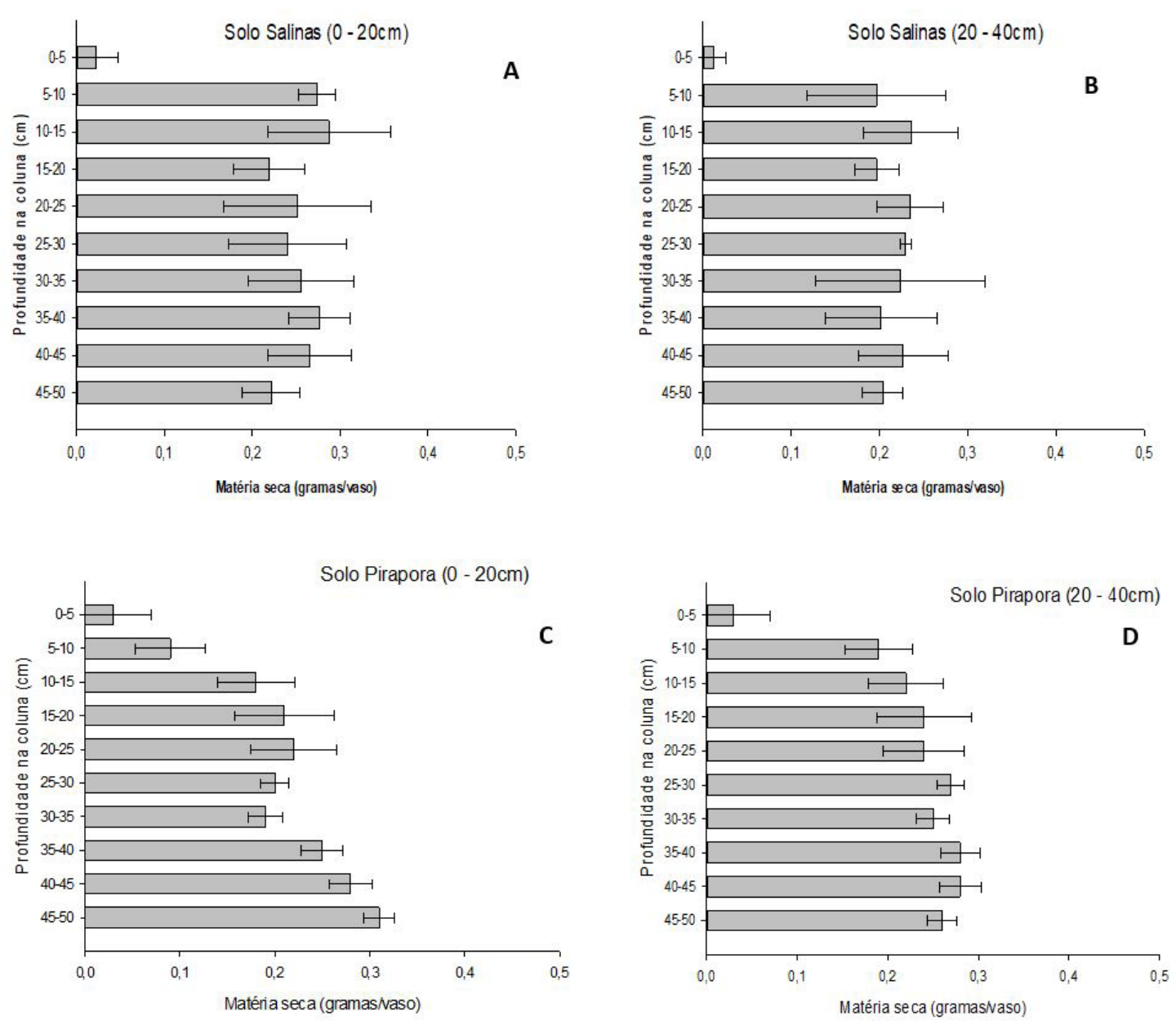

Figura 3. Massa da matéria seca de plantas de sorgo em diferentes profundidades das colunas, no solo de Salinas-MG coletados nas profundidades de (A) 0 a $20 \mathrm{~cm}$ e (B) 20 a $40 \mathrm{~cm}$ e no solo de Pirapora-MG coletados nas profundidades de (C) 0 a $20 \mathrm{~cm}$ e (D) 20 a $40 \mathrm{~cm}$, após aplicação de sulfentrazone e simulação de chuva de $60 \mathrm{~mm}$.

Embora moderada, a maior mobilidade do sulfentrazone no solo coletado na camada de 20-40 cm, pode ser atribuída principalmente ao menor teor de matéria orgânica, reduzindo os sítios de sorção do herbicida no solo, haja vista que outros atributos como CTC, $\mathrm{pH}$ teor de argila são semelhantes nas duas camadas do solo (Tabela 2).

Freitas et al. (2014), verificaram efeitos das características físico-químicas dos solos sobre o comportamento do sulfentrazone. Segundo estes autores, para recomendar esse herbicida, no intuito de garantir eficiência técnica e sustentabilidade ambiental, é necessário conhecer as características químicas e físicas dos solos, pois a sorção deste herbicida é muito influenciada pela textura, teor de matéria orgânica e $\mathrm{pH}$.

É importante salientar a influência do índice pluviométrico sobre a mobilidade de herbicidas no solo. Bachega et al. (2009), em ensaio utilizando colunas de solo, bioensaio e três lâminas de precipitação, verificaram que com o aumento do volume precipitado aumentava diretamente a mobilidade do sulfentrazone no solo, atingindo assim maiores profundidades. Logo, considerando que este herbicida apresenta longa persistência 
no solo, sendo detectado em área cultivada com cana-de-açúcar, por período superior a dois anos, quando aplicado na dose de $1,2 \mathrm{~L} \mathrm{ha}^{-1}$ (Blanco et al., 2010), o aumento na intensidade pluviométrica e/ou o acúmulo de chuvas após sua aplicação pode vir a ocasionar maior lixiviação do herbicida no perfil do solo que o verificado no presente trabalho, onde se aplicou $60 \mathrm{~mm}$.

Diante disso, verifica-se que se o herbicida ultrapassar a camada superficial $(0-20 \mathrm{~cm})$ atingindo camadas mais profundas, estas que de acordo com os resultados deste trabalho, possuem atributos que favorecem maior mobilidade deste ao longo do perfil do solo. Esse fato pode gerar uma série de consequências ambientais, tais como contaminação de águas subterrâneas e aumento do tempo de permanência do produto no solo. Além disso, há que se considerar que em camadas mais profundas a atividade microbiana, responsável por boa parte da degradação do herbicida, tem intensidade menor do que nas camadas superficiais, tornando a persistência nessas camadas ainda mais longa (Ghosh et al., 2016).

A lixiviação de defensivos agrícolas no perfil do solo tem implicações diretas na contaminação de recursos hídricos do subsolo, pois, uma vez retirados das camadas superficiais, onde há maior teor de matéria orgânica e atividade microbiana, sua persistência no ambiente pode ser intensamente prolongada (Sarmah et al., 1998; Prata et al.,2001)

\section{Conclusões}

O sulfentrazone foi detectado até $10 \mathrm{~cm}$ de profundidade do solo coletado na camada de 0-20 cm, com maior concentração nos primeiros cinco centímetros.

A maior mobilidade do sulfentrazone foi verificada na camada mais profunda do solo $(20-40 \mathrm{~cm})$ indicando maior potencial de lixiviação do herbicida nestas condições.

A matéria orgânica foi o atributo dos solos que mais influenciou na mobilidade do sulfentrazone.

\section{Referências}

Alfonso, L.F.; Germán, G.V.; María Del Carmen, P.C.; Hossein, G. Adsorption of organophosphorus pesticides in tropical soils: the case of karst landscape of northwestern Yucatan. Chemosphere, v.166, p.292-299, 2017. PMid:27700995. http:// dx.doi.org/10.1016/j.chemosphere.2016.09.109.

Bachega, T.F.; Pavani, M.C.D.; Alves, P.L.C.A.; Saes, L.P.; Boschiero, M. Lixiviação de sulfentrazone e amicarbazone em colunas de solo com adição de óleo mineral. Planta Daninha, v.27, n.2, p.363-370, 2009. http://dx.doi.org/10.1590/ S0100-83582009000200020.

Blanco, F.M.G.; Velini, E.D.; Batista Filho, A. Persistência do herbicida sulfentrazone em solo cultivado com cana-de-açúcar. Bragantia, v.69, n.1, p.71-75, 2010. http://dx.doi.org/10.1590/ S0006-87052010000100010.

Braga, D.F. Sorção, dessorção e lixiviação do sulfentrazone em solos da região canavieira do nordeste do Brasil. 2014. 91 f. Tese (Doutorado em Fitotecnia) - Universidade Federal Rural do Semiárido, Mossoró, 2014.

Carbonari, C.A.; Gomes, G.L.G.C.; Trindade, M.L.B.; Silva, J.R.M.; Velini, E.D. Dynamics of sulfentrazone applied to sugarcane crop residues. Weed Science, v.64, n.01, p.201-206, 2016. http:// dx.doi.org/10.1614/WS-D-14-00171.1.

Carter, A.D. Herbicide movement in soils: principles, pathways and processes. Weed Research, v.40, n.1, p.113-122, 2000. http:// dx.doi.org/10.1046/j.1365-3180.2000.00157.x.

ChemSpider. Sulfentrazone. Royal Society of Chemistry, 2017. Disponível em: <http://www. chemspider.com/Chemical-Structure.77887.html $>$. Acesso em: 3 jun. 2017.

Chen, P.Y. Table of key lines in X-ray powder diffraction patterns of minerals in clays and associated rocks. Bloomington: Indiana Geological 
Survey Report, 1977. 67p. (Geological Survey Occasional Paper, 21).

CONAB - Companhia Nacional de Abastecimento. Levantamentos de safra. 2015. Disponível em: <http://www.conab.gov.br/conteudos. php $? \mathrm{a}=1253 \& \mathrm{t}=\&$ Pagina_Objcmsconteudos $=1 \#$ A objcmsconteudos>. Acesso em: 8 nov. 2015.

Curran, W.S. Persistence of herbicides in soil. Crops and Soils, v.49, n.5, p.16-21, 2016. http:// dx.doi.org/10.2134/cs2016-49-0504.

EMBRAPA - Empresa Brasileira de Pesquisa Agropecuária. Manual de métodos de análise de solo. Rio de Janeiro, 1997. 212p.

Freitas, F.C.L.; Silva, A.A.; Silva, L.O.C.; Rocha, P.R.R.; Guimarães, F.C.N.; Freitas, M.A.M.; Felipe, R.S. Mobilidade do ametryn em solos da região semiárida do Rio Grande do Norte. Planta Daninha, v.30, n.3, p.641-648, 2012. http://dx.doi. org/10.1590/S0100-83582012000300021.

Freitas, M.A.M.; Passos, A.B.R.J.; Torres, L.G.; Moraes, H.M.F.; Faustino, L.A.; Rocha, P.R.R.; Silva, A.A. Sorção do sulfentrazone em diferentes tipos de solo determinada por bioensaios. Planta Daninha, v.32, n.2, p.385-392, 2014. http://dx.doi. org/10.1590/S0100-83582014000200016.

Ghosh, R.K.; Singh, N.; Singh, S.B. Effect of fly ash amendment on metolachlor and atrazine degradation and microbial activity in two soils. Environmental Monitoring and Assessment, v.188, n.8, p.482, 2016. PMid:27456695. http:// dx.doi.org/10.1007/s10661-016-5486-X.

Köppen, W.; Geiger, R. Klimate der Erde. Gotha: Verlag Justus Perthes, 1928. Wall-map $150 \mathrm{~cm} \times$ $200 \mathrm{~cm}$. Disponível em: <http://http://pt.climatedata.org//>. Acesso em: 30 out. 2015.

Melo, C.A.D.; Medeiros, W.N.; Tuffi Santos, L.D.; Ferreira, F.A.; Tiburcio, R.A.S.; Ferreira, L.R. Lixiviação de sulfentrazone, isoxaflutole e oxyfluorfen no perfil de três solos. Planta Daninha, v.28, n.2, p.385-392, 2010. http:// dx.doi.org/10.1590/S0100-83582010000200018.
Prata, F.; Lavorenti, A.; Regitano, J.B.; Tornisielo, V.L. Degradação e sorção de ametrina em dois solos com aplicação de vinhaça. Pesquisa Agropecuária Brasileira, v.36, n.7, p.975-981, 2001. http:// dx.doi.org/10.1590/S0100-204X2001000700007.

Prata, F.; Cardinali, V.C.B.; Lavorenti, A.; Tornisielo, V.L.; Regitano, J.B. Glyphosate sorption and desorption in soils with different phosphorous levels. Scientia Agrícola, v.60, n.1, p.175-180, 2003. http://dx.doi.org/10.1590/ S0103-90162003000100026.

Procópio, S.D.; Silva, A.A.; Santos, J.B.; Ferreira, L.R.; Miranda, G.V.; Siqueira, J.G. Efeito da irrigação inicial na profundidade de lixiviação do herbicida s-metolachlor em diferentes tipos de solo. Planta Daninha, v.19, n.3, p.409-417, 2001. http:// dx.doi.org/10.1590/S0100-83582001000300014.

Reddy, K.N.; Locke, M.A. Sulfentrazone sorption, desorption, and mineralization in soils from two tillage systems. Weed Science, v.46, n.4, p.494500, 1998.

Rodrigues, B.N.; Almeida, F.S. Guia de herbicidas. 4.ed. Londrina, 1998. 648p.

Sarmah, A.; Kookana, R.; Alston, A. Fate and behaviour of triasulfuron, metsulfuron-methyl and chlorsulfuron in the Australian soil environment: a review. Journal of Agricultural Research, v.49, p.775-790, 1998.

Silva, A.A.; Silva, J.F. Tópicos em manejo de plantas daninhas: herbicidas: comportamento no solo. 1.ed. Viçosa: Editora UFV, 2007. 367p.

Southwick, L.M.; Grigg, B.C.; Kornecki, T.S.; Fouss, J.L. Potential influence of sugarcane cultivation on estuarine water quality of Louisiana's gulf coast. Journal of Agricultural and Food Chemistry, v.50, n.15, p.4393-4399, 2002. PMid:12105976. http://dx.doi.org/10.1021/jf010051v.

Tanabe, A.; Mitobe, H.; Kawata, K.; Yasuhara, A.; Shibamoto, T. Seasonal and special studies on pesticides residues in surface eaters of the Shinano river in Japan. Journal of Agricultural 
and Food Chemistry, v.49, n.8, p.3847-3852, Tomlin, C.D.S. The pesticide manual: a world 2001. PMid:11513677. http://dx.doi.org/10.1021/ compendium. 15th. ed. Croydon: British Crop jf010025x. Protection Council, 2011. 1457p. 